\title{
Factors associated with refusal of hospital treatment at Odi District Hospital, Gauteng Province, South Africa
}

\author{
D K Nzaumvila, BSc, MD, MSc Med (Emerg Med), M Fam Med; L H Mabuza, MB ChB, BTh, M Fam Med, FCP(SA); M M Mogotsi, MSc Psych; \\ T Bongongo, MB ChB, MPH, M Fam Med; C N S Saidiya, MB ChB, MMed (Fam Med), FCFP (SA)
}

Department of Family Medicine and Primary Health Care, Sefako Makgatho Health Sciences University, Pretoria, South Africa

Corresponding author:DKNzaumvila (doug_nk@hotmail.com)

\begin{abstract}
Background. Ideally, medical consultation should be an opportunity for shared decision-making. In some instances, agreement between the doctor and patient may not be reached, and the consultation or admission could conclude with a refusal of hospital treatment (RHT). At Odi District Hospital in Gauteng Province, South Africa, patients refuse hospital admission either at the accident and emergency department or at the ward.

Objectives. To determine the reasons for and factors associated with RHT.

Methods. This was a retrospective review of patients' files.

Results. The institutional prevalence of RHT was $1.16 \%$. Of 223 reviewed patient files, the majority were males $(n=139 ; 86.05 \%)$, single $(n=152$; $68.16 \%)$ and unemployed $(n=163 ; 42.13 \%)$. The mean (standard deviation) age was 31.036 (17.297) years. A correlation between time of day and number of RHTs was noted ( $p=0.0413$ ). RHTs took place mainly at the emergency department (59.5\%). Familial reasons were recorded in $31.84 \%$ of cases. There was an association between age and previous admission $(p<0.0001,95 \%$ confidence interval $(\mathrm{Cl}) 0.1071-0.2451)$ and with comorbidities $(p=0.0072, \mathrm{Cl} 0.4222-0.8647)$. Surgical RHT was associated with ward stay $(p<0.0001, \mathrm{Cl} 3.238-11.051)$, and first-time consultation ( $p=0.0033,95 \% \mathrm{Cl} 0.4592-0.6880)$. Medical RHT showed an association with age $(p<0.0001, \mathrm{Cl} 0.08014-0.2753)$, stay in the ward $(p=0.0003, \mathrm{Cl} 1.382-3.275)$ and comorbidities $(p<0.0001,95 \% \mathrm{Cl} 2.2015-4.486)$.

Conclusion. Since RHT is the patient's protected right, the challenge is for the healthcare worker to inform the patient adequately to enable him or her to exercise it safely. More needs to be done to improve healthcare worker-doctor communication for collaboration regarding RHT.
\end{abstract}

S Afr J Bioethics Law 2020;13(2):1 19-124. https://doi.org/10.7196/SAJBL.2020.v13i2.688

Ideally, medical consultation should be an opportunity for shared decision-making. This means that treatment options should be discussed with the patient, with sufficient information being provided on their risks and benefits, as well as acknowledgement of the patient's preferences. ${ }^{[1]}$ In the best-case scenario this will eventually end in an agreement between the patient or his/her relatives and the doctor. Unfortunately, this is not always the case. In some instances, agreement between the doctor and patient may not be reached, and the consultation or admission could result in a refusal of hospital treatment (RHT), also known as discharge against medical advice (DAMA) or leaving against medical advice (LAMA). ${ }^{[2]}$ This is a situation where a patient chooses to leave the hospital before the treating physician recommends discharge. ${ }^{[2,3]}$

Although patient autonomy is involved here, RHT can affect doctor-patient relationships and generate frustration. ${ }^{[1,2]}$ This is a worldwide problem that varies in degree from one country to another, as well as according to different types of medical conditions, and race. A report on RHT in the USA mentioned a rate of $2 \%{ }^{[4]}$ Literature in the European Union showed low prevalence rates: in Spain, it was $0.34 \%$ of admitted patients. ${ }^{[2,5]}$ Estimations from Nigeria ranged from $1.2 \%$ to $5.7 \%{ }^{[6-8]}$ Lower socioeconomic class, male gender, younger age, and substance abuse were consistently associated with RHT. ${ }^{[2]}$ Psychiatric patients are reported to be the most prone to RHT, with a prevalence rate of above $50 \% .{ }^{[9]}$ In addition, patients with opportunistic infections associated with HIV have been reported to be prone to RHT. ${ }^{[2,9]}$ According to previous studies, some of the reasons provided include factors such as financial issues and diseases within the family, financial obligations and improved health. ${ }^{[2,10]}$ Some studies have found that social support from family and friends was also associated with a low prevalence of $\mathrm{RHT}^{[10,11]}$

At Odi District Hospital in Gauteng Province, South Africa (SA), patients refuse hospital admission either while at the outpatients department or at the accident and emergency ( $A$ and $E$ ) department, or even after admission. The National Health Act No. 61 of 2003 in SA gives patients the right to information about their condition and the treatment options available to them, and the right to refuse health services. ${ }^{[12]}$ This comes with some challenges and issues specific to SA. ${ }^{[12,13]}$

\section{Objectives}

The objective of the study was to determine the reasons for and factors associated with RHT at Odi District Hospital.

\section{Methods}

Odi District Hospital is located in Mabopane Township in Tshwane, Gauteng Province, SA. It is a 227-bed hospital that has been operating for the last 25 years. It renders a 24-hour service with its theatre, maternity unit and emergency room (casualty). It also offers the 
following services: general and specialised outpatient departments; internal medicine; paediatrics; obstetrics and gynaecology; and surgery. Some specialised clinics are run by allied professionals (dietician, eye and dental clinics, audiologist, physiotherapist, occupational health and safety clinic, reproductive health wellness). It drains from 19 clinics around Tshwane, with the Dr George Mukhari Academic Hospital as its referral hospital.

We conducted a retrospective descriptive study over a period of 24 months (2017 and 2018) of files reviewed at Odi District Hospital. We retrieved the file numbers of patients who signed RHTs from the registers of the $A$ and $E$ department and various wards. As a descriptive study, we used means and standard deviations (SD) for parametric data, and medians and confidence intervals (CI) for nonparametric data. Percentages, frequencies and ratios were used for categorical and non-categorical data. We used Fisher's exact test to compare categorical data, and $p<0.05$ was considered statistically significant.

\section{Ethical consideration}

Authorisation to conduct this study was obtained from the Chief Executive Officer of Odi District Hospital, and the ethics committee of the Sefako Makgatho Health Sciences University (ref. no. SMUREC/ M/85/2015:IR) and Tshwane Ethical Research Committee (ref. no. GP 2016RP43 38).

\section{Results}

We listed 241 files of cases of RHT: 237 (98.34\%) were retrieved, and of these 223 (92.53\%) were suitable for analysis, covering the 2-year period. There were 72 (32.29\%) files in 2017 and 151 (67.71\%) in 2018. During the study period, there was a total of 9609 discharges in 2017, and 9627 discharges in 2018. The global institutional incidence of RHT was 1.16\%: $0.75 \%$ in 2017, and 1.57\% in 2018.
Baseline characteristics of RHT cases showed that the predominant groups were were males ( $n=139 ; 86.05 \%, p<0.0001,95 \%$ confidence interval (Cl) $1.313-1.440)$, single $(n=152 ; 68.16 \%, p<0.0001,95 \% \mathrm{Cl}$ $1.675-1.814)$ and unemployed $(n=163 ; 42.13 \%, p<0.0001,95 \% \mathrm{Cl}$ 1.680 - 1.854) (Table 1).

The mean (SD) of the age distribution was 31.036 (17.297) years $(p<0.0490,95 \% \mathrm{Cl} 28.912-33.439)$, and more than half (52.9\%) were aged between 24 and 43 years, with the youngest and the oldest being aged 2 days and 96 years, respectively.

The review of the characteristics of cases of RHT revealed that there was a correlation between the time of day (more frequent late in the day than in the early hours) and number of RHTs, with a $p$-value of 0.0413 (Fig. 1).

The day distribution $(p<0.0001,95 \% \mathrm{Cl} 3.754-4.291)$ showed that RHT was elevated on Fridays and Tuesdays ( 36 or $16.14 \%, p=0.0051$, $95 \% \mathrm{Cl} 6.435$ - 7.321). During weekends and public holidays there were 75 RHTs (33.63\%), compared with 148 RHT (66.37\%) on working days.

Close to $70 \%$ of RHTs were signed at the A and E department ( $n=155, p<0.0001,95 \% \mathrm{Cl} 2.206-2.448$ ). In terms of the types of diagnosis, in general $145(65.02 \%)$ were provisional $(p<0.0001,95 \%$ $\mathrm{Cl} 1.287$ - 1.413). The distribution of different diagnoses highlighted that 78 cases $(35 \%)$ had a surgical diagnosis $(p<0.0001,95 \% \mathrm{Cl}$ 4.567 - 5.254). In $82.06 \%$ of the cases, RHT was requested and signed by the patient him/herself; the patients were never admitted in $78.02 \%$ of cases, and $60.54 \%$ did not have any chronic conditions. Among these patients, only 17 (7.63\%) had a previously signed RHT, and 67 (34.08\%) were consulted or admitted after the RHT (Table 2). Although the cause of RHT was not documented in 84 (37.67\%) cases, familial reasons were recorded in 71 (31.84\%) cases (Table 3).

Bivariate analysis showed that there was an association between age and previous admission ( $p<0.0001,95 \% \mathrm{Cl} 0.1071-0.2451)$ and having any comorbidities $(p=0.0072,95 \% \mathrm{Cl} 0.4222-0.8647)$. Surgical

Table 1. Baseline characteristics of cases of refusal of hospital treatment ( $N=223$ )

\begin{tabular}{|c|c|c|c|}
\hline & $2017, n(\%)$ & 2018, n (\%) & \\
\hline Characteristic & $N=72(32.29)$ & $N=151(67.71)$ & Total, $\boldsymbol{n}(\%)$ \\
\hline \multicolumn{4}{|l|}{ Gender } \\
\hline Female & $29(40.28)$ & $55(36.42)$ & $84(37.67)$ \\
\hline Male & $43(59.12)$ & $96(63.58)$ & $139(62.33)$ \\
\hline \multicolumn{4}{|l|}{ Marital status } \\
\hline Married & $18(25)$ & 47 (31.13) & 65 (29.15) \\
\hline Not documented & $1(1.39)$ & $3(1.99)$ & $4(1.79)$ \\
\hline Widower & 0 & $2(1.32)$ & $2(0.9)$ \\
\hline \multicolumn{4}{|l|}{ Age (years) } \\
\hline $14-23$ & $11(15.28)$ & $18(11.92)$ & $29(13.0)$ \\
\hline $24-33$ & $14(19.44)$ & $17(11.26)$ & 31 (13.9) \\
\hline $34-43$ & $20(27.78)$ & $57(37.75)$ & 77 (34.53) \\
\hline $44-53$ & $8(11.11)$ & 19 (12.58) & $27(12.1)$ \\
\hline$\geq 54$ & $9(12.5)$ & $9(5.96)$ & $18(8.07)$ \\
\hline \multicolumn{4}{|l|}{ Occupation } \\
\hline Employed & $12(16.67)$ & $59(39.07)$ & $71(31.84)$ \\
\hline Unemployed & $58(80.56)$ & $85(56.29)$ & $143(62.13)$ \\
\hline Self-employed & $1(1.39)$ & $1(0.66)$ & $2(0.9)$ \\
\hline Learner/student & $1(1.39)$ & $6(3.97)$ & $7(3.14)$ \\
\hline
\end{tabular}




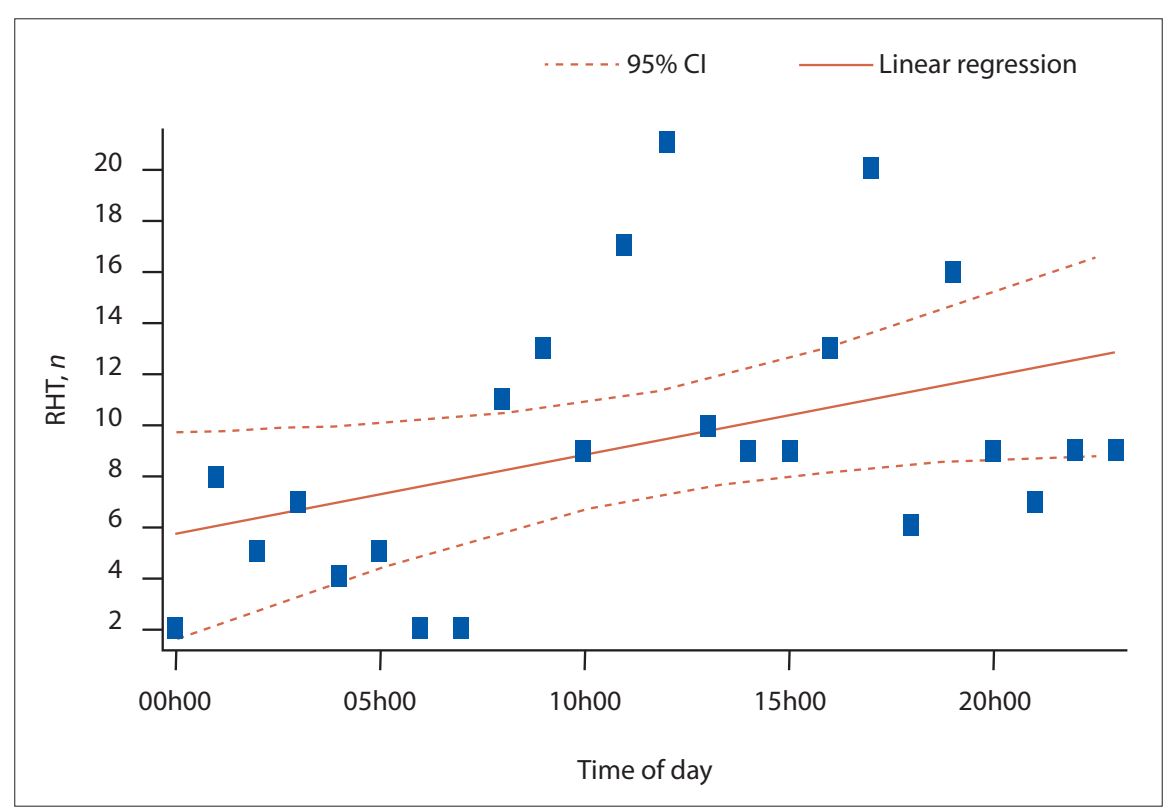

Fig. 1. Regression analysis of number of refusal of hospital treatments (RHTs) by time of day. $(C l=$ confidence interval.)

RHT was associated with length of stay in the ward and first-time consultation $(p<0.0001$ $95 \% \mathrm{Cl} 3.238-11.051$; and $p=0.0033,95 \% \mathrm{Cl}$ $0.4592-0.6880$, respectively). Medical RHT showed an association with age $(p<0.0001$, $95 \% \mathrm{Cl} 0.08014-0.2753)$, with the length of stay in the ward $(p=0.0003,95 \% \mathrm{Cl}$ $1.382-3.275)$ and with other comorbidities $(p<0.0001,95 \% \mathrm{Cl} 2.2015$ - 4.486).

\section{Discussion}

The global institutional prevalence of RHT for both years was $1.16 \%$. The literature reports a wide range of prevalences, which vary according to the setting, but are usually in single digits. ${ }^{[2-7]}$ The exception here are psychiatric institutions, where double digits and even up to $50 \%$ rates of RHT have been reported. ${ }^{[2,9,10]}$ The annual prevalence of RHT at Odi District Hospital increased from 0.75\% in 2017 to $1.57 \%$ in 2018, doubling from 72 cases in 2017 to 151 in 2018. Different frequencies and trends in RHT are reported in the literature. ${ }^{[14,15]}$ The possibility of retrieving data from previous years to analyse trends in RHT at Odi District Hospital was made difficult by the poor storage of records and poor quality of the records themselves.

While analysis of data (baseline characteristics and RHT characteristics) for both years showed no difference (Tables 1 and 2), Table 3 showed a disparity in the trend of reasons given for RHT in 2017 and 2018; however, this was not significant ( $p=0.8289,95 \% \mathrm{Cl} 14.602$ - 18.006). RHT for family reasons more than doubled, from $18.06 \%$ in 2017 to $38.41 \%$ in 2018 , whereas RHT for personal reasons dropped by half, from $22.22 \%$ in 2017 to $10.6 \%$ in 2018 . Although refuted by Greenberg et al., ${ }^{[16]}$ drug use is among other predictors for RHT reported by other studies. ${ }^{[3,5,7,10,16-19]}$ This study did not provide evidence of substance use among the patients who signed RHTs; however, given the fact that drug use has been increasing in the areas drained by Odi District Hospital, and that gender and age characteristics remain the same, ${ }^{[20-22]}$ one may consider this as one of the factors that may be associated with the increase in RHT that was seen.

Analysis of the baseline characteristics showed that males were far more likely to give RHT; also, most of the RHT patients were single, with a poor economic background. The finding regarding male gender in this study confirmed the consistency across the RHT literature. ${ }^{[2,4-7,9-11,15-20]}$ Exceptions are found in some paediatric populations.$^{[8]}$ It is unmistakably important to understand that it is possible to identify those at greater risk of $\mathrm{RHT}$, and therefore to be able to take earlier action to prevent the unnecessary morbidity and mortality related to men choosing to disregard their doctors' opinion and leave the hospital. There are currently no data that can scientifically ascertain why males are more prone to RHT than females.

Many published data on RHT did not report the marital status of patients, ${ }^{[3-5]}$ when reported, the findings were varied. For example, one study reported a high prevalence of RHT of $24 \%$ among the married v. $17 \%$ among the single, ${ }^{[10]}$ in contrast with the $68.16 \%$ of single patients in this study. The explanation for this discrepancy may be found in the setting and the average age of the population of patients who refused hospital treatment.

\section{Characteristics of RHT}

Analysis of the characteristics of RHT at Odi District Hospital showed correlation between the time and number of RHTs $(p=0.0413)$, as shown in Fig. 1, meaning that as time moves on from sunrise to sunset, there are more cases of RHT. There should be an explanation for this trend. This study showed that many patients were from the low-income social category and were unemployed (more than two-thirds), which was comparable to other publications on RHT. ${ }^{[2-5,7,11]}$ Among other reasons, unemployed persons were probably living from hand to mouth, and taking on piece jobs when they could get them. Green et al. ${ }^{[1]]}$ acknowledged that financial/personal obligations are a factor in $\mathrm{RHT}$. The longer patients spend in hospital, the more opportunities for piece jobs they may lose. This supports the fact that personal reasons were the cause of many RHTs. Another issue is the quality of the relationship between patients (during their stay in the hospital) and healthcare workers. Mabuza et al. ${ }^{[23]}$ reported some difficulties for patients in communicating with the healthcare workers directly implicated in their management.

Many RHTs were still at a stage of provisional diagnosis, and a significant number were made at the emergency room or the wards, although there was no significant difference, which concurs with previous studies. ${ }^{[5,8]}$ Without ignoring the fact that the patient's right to RHT is protected by the law, ${ }_{1}^{[12]}$ the quality of consent can be questioned. An ethical problem arises as to why a patient with an acute or emergency need for medical attention would refuse treatment. The decision to leave the hospital against medical advice is based on patient autonomy, and overrides beneficence. ${ }^{[3,13]}$ However, the real ethical issue here may be maleficence: did the patient or relatives have enough information before signing an RHT? This brings us to the concept of informed refusal. ${ }^{[13]}$ Informed refusal is regarded as the 


\section{ARTICLE}

Table 2. Characteristics of refusal of hospital treatment ( $N=223$ )

\begin{tabular}{|c|c|c|c|}
\hline Characteristic & $\begin{array}{l}2017, n(\%) \\
N=72(32.29)\end{array}$ & $\begin{array}{l}2018, n(\%) \\
N=151(67.71)\end{array}$ & Total, $\boldsymbol{n}(\%)$ \\
\hline \multicolumn{4}{|l|}{ Days } \\
\hline Monday & $7(9.72)$ & $26(17.22)$ & $33(14.8)$ \\
\hline Tuesday & $11(15.28)$ & $25(16.56)$ & $36(28.84)$ \\
\hline Wednesday & $2(2.78)$ & $21(13.91)$ & $23(10.31)$ \\
\hline Thursday & $13(18.06)$ & $16(10.6)$ & $29(13.00)$ \\
\hline Friday & $11(15.28)$ & 25 (16.56) & $36(16.14)$ \\
\hline Saturday & $16(22.22)$ & $18(13.24)$ & $34(15.25)$ \\
\hline Sunday & $12(16.67)$ & $20(1.99)$ & $32(13.35)$ \\
\hline Weekends and public holidays & $29(40.28)$ & $46(30.46)$ & $75(33.63)$ \\
\hline Working days & $43(59.72)$ & $95(69.54)$ & $148(66.37)$ \\
\hline \multicolumn{4}{|l|}{ Department } \\
\hline Emergency & $58(80.56)$ & $97(64.24)$ & $155(69.51)$ \\
\hline Gynaecology & $1(1.34)$ & 0 & $1(0.45)$ \\
\hline Medical & $4(5.56)$ & $15(9.93)$ & $19(8.52)$ \\
\hline Orthopaedics & 0 & $1(0.66)$ & $1(0.45)$ \\
\hline Paediatrics & $1(1.34)$ & $8(5.30)$ & $9(4.04)$ \\
\hline Surgical & $8(11.11)$ & $30(19.87)$ & $38(17.04)$ \\
\hline Type of diagnosis & 49 (68.06) & $96(63.58)$ & $145(65.02)$ \\
\hline Confirmed diagnosis & $23(31.94)$ & $55(37.42)$ & $78(34.98)$ \\
\hline \multicolumn{4}{|l|}{ Working diagnosis } \\
\hline \multicolumn{4}{|l|}{ Diagnosis } \\
\hline Gynaecological & $3(4.17)$ & $11(7.28)$ & $14(6.28)$ \\
\hline Medical & $27(37.5)$ & $47(31.13)$ & $74(33.18)$ \\
\hline Medico-surgical & $1(1.39)$ & $1(0.66)$ & $2(0.9)$ \\
\hline Obstetric & $1(1.39$ & 0 & $1(0.45)$ \\
\hline Orthopaedic & $1(1.39)$ & $6(3.97)$ & $7(3.14)$ \\
\hline Paediatric & $4(5.56)$ & $15(9.93)$ & $19(8.52)$ \\
\hline Surgical & $18(25)$ & $60(39.73)$ & $78(35.0)$ \\
\hline Trauma & $16(22.22)$ & $11(7.28)$ & $27(12.11)$ \\
\hline Urology & $1(1.39)$ & 0 & $1(0.45)$ \\
\hline \multicolumn{4}{|l|}{ Person signing the RHT } \\
\hline Guardian/parent/relative & $13(18.06)$ & $27(17.88)$ & $40(17.94)$ \\
\hline Patient & $59(81.94)$ & $124(82.12)$ & $183(82.06)$ \\
\hline \multicolumn{4}{|l|}{ Admission history at Odi Hospital } \\
\hline Never & $60(83.33)$ & $114(75.5)$ & $174(78.02)$ \\
\hline Previously admitted & $12(16.67)$ & $37(24.5)$ & $59(21.98)$ \\
\hline \multicolumn{4}{|l|}{ Previous RHT } \\
\hline Yes & $7(9.72)$ & $10(6.62)$ & $17(7.63)$ \\
\hline No & $65(90.28)$ & $141(93.47)$ & $206(92.37)$ \\
\hline \multicolumn{4}{|c|}{ Consultation and/or admission after RHT } \\
\hline Yes & $22(30.56)$ & $54(35.76)$ & $76(34.08)$ \\
\hline No & $50(69.44)$ & $97(64.24)$ & $147(65.92)$ \\
\hline \multicolumn{4}{|l|}{ Existence of chronic disease } \\
\hline Yes & $22(30.56)$ & $66(43.71)$ & $88(39.46)$ \\
\hline No & $50(69.44)$ & $85(56.29)$ & $135(60.54)$ \\
\hline
\end{tabular}

antithesis of informed consent, where the possible complications of $\mathrm{RHT}$ are discussed by the healthcare worker and the patient in great detail before the RHT is signed. ${ }^{[24]}$ This is not done in order to change the patient's mind, but to make sure the relevant information is provided to the patient before (s)he leaves the hospital. It is the duty of the healthcare worker to guarantee that the discharge is as secure and suitable as possible under the circumstances. This also involves assisting the patient with follow-up after $\mathrm{RHT}{ }^{[5]}$ This followup does not necessarily mean that the patient has to come back to the same hospital - the healthcare worker must advise him/her to look for help at another healthcare institution of his/her choice. Finally, a phone call should be made within a reasonable time of $\mathrm{RHT}$, in order to make sure that the patient is not in any danger. If this is not done, it could be considered maleficence. 


\section{ARTICLE}

Table 3. Reason for refusal of hospital treatment, and healthcare workers involved $(N=223)$

\begin{tabular}{|c|c|c|c|}
\hline & $2017, n(\%)$ & $2018, n(\%)$ & \\
\hline Characteristic & $N=72(32.29)$ & $N=151(67.71)$ & Total, $n$ (\%) \\
\hline \multicolumn{4}{|l|}{ Reasons for RHT } \\
\hline Family reasons & $13(18.06)$ & $58(38.41)$ & $71(31.84)$ \\
\hline Going to private hospital & $1(1.39)$ & $3(2)$ & $4(1.79)$ \\
\hline Going to consult a sangoma (traditional healer) & $2(2.78)$ & $8(5.3)$ & $10(4.48)$ \\
\hline No improvement & $1(1.39)$ & $1(0.66)$ & $2(0.9)$ \\
\hline Not documented & $35(48.61)$ & $49(32.45)$ & $84(37.67)$ \\
\hline Personal reasons & $16(22.22)$ & $16(10.6)$ & $32(14.4)$ \\
\hline Second opinion & $2(2.78)$ & $6(3.97)$ & $8(3.59)$ \\
\hline Trust issue & 0 & $1(0.66)$ & $1(0.45)$ \\
\hline Unhappy with treatment & $1(1.39)$ & $6(3.97)$ & $7(3.14)$ \\
\hline Work related & $1(1.39)$ & $3(2)$ & $4(1.79)$ \\
\hline \multicolumn{4}{|l|}{ Medical personnel } \\
\hline Clinical associate alone & $1(1.39)$ & $1(0.66)$ & $2(0.9)$ \\
\hline Clinical associate and doctor & 0 & $1(0.66)$ & $1(0.45)$ \\
\hline Clinical associate and nurse & $1(1.39)$ & 0 & $1(0.45)$ \\
\hline Doctor alone & $17(23.21)$ & $9(5.96)$ & $26(11.66)$ \\
\hline Doctor and nurse & $53(73.61)$ & $123(81.45)$ & $176(78.92)$ \\
\hline Nurse alone & 0 & $17(11.26)$ & $7(7.62)$ \\
\hline
\end{tabular}

\section{Table 4. Bivariate analysis}

\begin{tabular}{ll}
\hline Variable & $\boldsymbol{p}$-value $(95 \% \mathrm{Cl})$ \\
\hline Age & \\
Previous admission & $<0.0001(0.1071-0.2451)$ \\
Chronic condition & $0.0072(0.4222-0.8647)$ \\
Previous RHT & $0.4570(0.279-1.740)$ \\
Types of diagnosis & $0.6723(0.596-0.7275)$ \\
Consultation or admission post RHT & $0.5695(0.7834-1.653)$ \\
First-time consultation & $0.0542(1.003-1.439)$ \\
Surgical diagnosis in ward & \\
Age & $0.4807(0.7049-1.168)$ \\
Stay & $<0.0001(3.238-11.051)$ \\
Previous RHT & $0.1782(0.3791-1.189)$ \\
Chronic conditions & $0.0620(0.4767-1.019)$ \\
Types of diagnosis & $0.3041(0.7208-1.103)$ \\
Consultation or admission post RHT & $1.0000(0.3898-2.638)$ \\
First-time consultation & $0.0033(0.4592-0.6880)$ \\
Medical diagnosis & \\
Age & $<0.0001(0.0801-0.2753)$ \\
Stay in the ward & $0.0003(1.382-3.275)$ \\
Previous RHT & $0.6078(0.5179-3.170)$ \\
Chronic conditions & $<0.0001(2.2015-4.486)$ \\
Types of diagnosis & $0.2970(0.8390-1.927)$ \\
Consultation or admission post RHT & $0.4539(0.8055-1.721)$ \\
First-time consultation & $0.7547(0.650-1.390)$ \\
Previous RHT & \\
Consultation and/or admission post RHT & $<0.001(-0.2646-9.151)$ \\
Chronic condition & $<0.001(-0.3184-11.012)$ \\
Consultation and/or admission post RHT & \\
First-time consultation & $<0.001(-0.3632-12.563)$ \\
Chronic condition & $0.05(-0.05381-1.861)$
\end{tabular}

$\mathrm{Cl}=$ confidence interval $; \mathrm{RHT}=$ refusal of hospital treatment.

\begin{tabular}{lll}
\multicolumn{3}{l}{ Table 5. Predicting factors for RHT and return after RHT } \\
\hline Variable & Odds ratio $(95 \%$ Cl $)$ & $\boldsymbol{p}$-value \\
\hline First-time consultation & & \\
Age & $1.839(1.029-3.287)$ & 0.0542 \\
Chronic disease & $0.3771(0.2091-0.6802)$ & 0.0015 \\
Drainage area & $1.126(0.6047-2.097)$ & 0.7499 \\
Employed & $0.7477(0.4075-1.372)$ & 0.3498 \\
Gender & $0.6087(0.3207-1.155)$ & 0.1608 \\
Length of stay & $0.5085(0.2756-0.9381)$ & 0.0359 \\
Married & $0.8736(0.4758-1.604)$ & 0.7547 \\
Medical & $2.138(0.1012-45.180)$ & 1.000 \\
Self-employed & $2.358(1.292-4.302)$ & 0.0071 \\
Single & $0.4018(0.2219-0.7276)$ & 0.0033 \\
Surgical & $6.061(1.392-26.392)$ & 0.0062 \\
Trauma & $1.446(0.8016-2.608)$ & 0.2264 \\
Consultation and/or & & \\
admission after RHT & & \\
Age & $1.2169(0.6937-2.131)$ & 0.5695 \\
Chronic disease & $0.6704(0.234-0.3676)$ & 0.2130 \\
Drainage area & $8.821(4.689-16.595)$ & $<0.0001$ \\
Employed & $0.5912(0.3184-1.098)$ & 0.0994 \\
Gender & $0.4954(0.2807-0.8743)$ & 0.0194 \\
Length of stay & $0.4670(0.2646-0.8244)$ & 0.0093 \\
Married & $1.087(0.5916-1.990)$ & 0.8766 \\
Medical & $1.322(0.7378-2.370)$ & 0.3689 \\
Self-employed & $1.947(0.1200-31.52)$ & 1.000 \\
Single & $0.9291(0.5139-1.680)$ & 0.8797 \\
Surgical & $0.8442(0.47-1.515)$ & 0.6581 \\
Trauma & $0.2995(0.0990-0.9007)$ & 0.0293 \\
Unemployed & $1.646(0.9072-2.985)$ & 0.1082
\end{tabular}

$\mathrm{RHT}=$ refusal of hospital treatment $\mathrm{Cl}=$ confidence interval. 
RHT for familial reasons outnumbered the other reasons for RHT. Although this finding is not new in RHT literature, ${ }^{[11]}$ associations between variables provide a better overall view of the situation. Bivariate analysis highlighted that the younger the patients were, the more prone they were to RHT if they had had a previous admission to Odi District Hospital or had a comorbidity. Therefore, could 'personal reasons' in fact be expressing personal experience? Further studies are needed in order to clarify this point.

\section{Limitation}

This was a retrospective file review study, where healthcare workers reported what happened, hence patients' opinions could not be appraised.

\section{Conclusion}

RHT is a protected freedom, which makes it a right. Therefore, it is an obligation for any healthcare worker to assist a patient to exercise their Constitutional right. On the one hand, optimising a good relationship between healthcare workers and patients at Odi District Hospital will allow patients to use their autonomy, with sufficient and adequate information concerning their condition, while on the other, it will maximise efforts to identify patients at risk of RHT to allow early intervention. A future prospective study on RHT at Odi District Hospital would bring more factors to light, and could focus on the feelings and opinions of patients who sign RHTs.

Acknowledgements. We would like to thank the management of Odi District Hospital who made the files available to us for this study.

Author contributions. DN: conceived the study, developed the protocol, collected data, analysed data, drafted the article, uploaded to the journal. HM: reviewed the protocol, reviewed the collected data, reviewed the analysed data and reviewed the drafted article. MM: reviewed the protocol, reviewed the collected data, reviewed the analysed data and reviewed the drafted article. BT: reviewed the collected data, analysed data and reviewed the drafted article. CNS: reviewed the collected data, analysed data and reviewed the drafted article.

\section{Funding. None.}

Conflicts of interest. None.

1. De Villiers M. The consultation - a different approach to the patient. In: Mash B, ed. Handbook of Family Medicine. Cape Town: Oxford University Press, 2006:42-64.

2. Paul G, Gautam PL, Mahajan RK, Gautam N, Ragavaiah. Patients leaving against medical advice - a national survey. Indian J Crit Care Med 2019;23(3):143-148. https://doi.org/10.5005\%2Fjp-journals-10071-23138

3. Fadare ACJ. Discharge against medical advice: Ethico-legal implications from an African perspective. S Afr J Bioethics Law 2012;5(2):98-101.
4. Alfandre DJ. 'I'm going home': Discharges against medical advice. Mayo Clin Proc 2009;84:255-260.

5. Ibrahim SA, Kwoh CK, Krishnan E. Factors associated with patients who leave acutecare hospitals against medical advice. Am J Public Health 2007;97(12):2204-2208. https://doi.org/10.2105/ajph.2006.100164

6. Duñó R, Pousa E, Sans J, Tolosa C, Ruiz A. Discharge against medical advice at a general hospital in Catalonia. Gen Hosp Psychiatry 2003;25:46-50. https://doi. org/10.1016/S0163-8343(02)00253-0

7. Udosen AM, Glen E, Ogbudu S, Nkposong E. Incidence of leaving against medical advice (LAMA) among patients admitted at the accident and emergency unit of the University of Calabar Teaching Hospital, Calabar, Nigeria. Niger J Clin Pract 2006;9(2):120-123.

8. Onyiriuka AN. Discharge of hospitalised under-fives against medical advice in Benin City, Nigeria. Niger J Clin Pract 2007;10:200-204.

9. Chan AC, Palepu A, Guh DP, et al. HIV-positive injection drug users who leave the hospital against medical advice: The mitigating role of methadone and social support. J Acquir Immune Defic Syndr 2004;35(1):56-59. https://doi. org/10.1097/00126334-200401010-00008

10. Brook M, Hilty DM, Liu W, Hu R, Frye MA. Discharge against medical advice from inpatient psychiatric treatment: A literature review. Psychiatr Serv 2006:57(8):11921198. https://doi.org/10.1176/ps.2006.57.8.1192

11. Green P, Watts D, Poole $S$, Dhopesh V. Why patients sign out against medical advice (AMA): Factors motivating patients to sign out AMA. Am J Drug Alcohol Abuse 2004;30(2):489-493. https://doi.org/10.1081/ada-120037390

12. South Africa. National Health Act No. 61 of 2003. http://www.info.gov.za/ documents/ acts/2003.htm (accessed 18 October 2013).

13. Nienaber A, Bailey KN. The right to physical integrity and informed refusal: Just how far does a patient's right to refuse medical treatment go? S Afr J Bioethics Law 2016;9(2):73-74. https://doi.org/10.7196\%2FSAJBL.2016.v9i2.472

14. Chima SC. Evaluating the quality of informed consent and contemporary clinical practices by medical doctors in South Africa: An empirical study. BMC Med Ethics 2013;14(Suppl 1):S1-S9. https://doi.org/10.1186/1472-6939-14-S1-S3

15. Saia M, Buja A, Mantoan D, et al. Frequency and trends of hospital discharges against medical advice (DAMA) in a large administrative database. Ann Ist Super Sanità 2014;50:357-362. https://doi.org/10.4415/ann_14_04_11

16. Greenberg WM, Otero J, Villanueva L. Irregular discharges from a dual diagnosis unit. Am J Drug Alcohol Abuse 1994;20(3):355-371. https://doi. org/10.3109/00952999409106020

17. Said Al, Kent K, Eswar K. Factors associated with patients who leave acute-care hospitals against medical advice. Am J Public Health 2007;97:2204-2208. https:// doi.org/10.2105/AJPH.2006.100164

18. Jeremiah J, O'Sullivan P, Stein MD. Who leaves against medical advice? J Gen Intern Med 1995;10:403-405. https://doi.org/10.1007/bf02599843

19. Saitz R. Discharges against medical advice: Time to address the causes. CMA 2002;167(6):647-648.

20. De los Cobos JP, Trujols J, Ribalta E, Casas M. Cocaine use immediately prior to entry in an inpatient heroin detoxification unit as a predictor of discharges against medical advice. Am J Drug Alcohol Abuse 1997;23:267-279. https://doi. org/10.3109/00952999709040946

21. Mokwena K. 'Consider our plight': A cry for help from nyaope users. Health SA Gesondheid 2016;21:137-142. https://doi.org/10.1016/j.hsag.2015.09.001

22. Khine AA, Mokwena KE. Drug interactions in the constituents of street drug mixture 'nyaope' in South Africa: A mini-review. Afr J Drug Alcohol Studies 2016;15(2):92-101.

23. Mabuza LH, Omole OB, Govender I, Ndimande JV. Reasons for inpatients not to seek clarity at Dr George Mukhari Academic Hospital, Pretoria. Afr J Prim Health Care Fam Med 2014;6(1):a576. https://doi.org/10.4102\%2Fphcfm.v6i1.576

24. Klauer K. Informed refusal: Just as important as informed consent. Relias Media, 2013. https://www reliasmedia.com/articles/64232-informed-refusal-just-asimportant-as-informed-consent (accessed 18 June 2019).

Accepted 25 August 2020 